\title{
Reconciling Pluralism and Consensus as Political Ideals
}

\author{
John S. Dryzek Australian National University \\ Simon Niemeyer Australian National University
}

\begin{abstract}
While consensus is often taken to be the ideal way to secure political legitimacy, a more robust pluralism has many defenders too. We attempt to reconcile arguments for pluralism and consensus. Pluralism ought to be accepted and valued at the simple level of values, beliefs, and preferences. Pluralism at this level can nevertheless coexist with normative, epistemic, and/or preference meta-consensus, all of which have qualities that should attract even pluralists. However, close attention must be paid to the content of meta-consensus and the conditions of its production or discovery.
\end{abstract}

$\mathrm{P}$ luralism and consensus are political ideals of long standing that seem to point in opposite directions. That their reconciliation is desirable is shown by the fact that unbridled pluralism and absolute consensus alike turn out on closer inspection to have few advocates or defenders. That their reconciliation is difficult is shown by widespread suspicion that any alleged resolution of their tension ends up privileging one side or the other. Here we explore the case for a resolution that privileges both—but at different levels. This resolution will involve pluralism in values, beliefs, and preferences in the context of a metaconsensus on one or more of these three aspects, though both its content and the way in which meta-consensus is produced turn out to require critical scrutiny.

We begin by examining some of the more prominent contemporary advocates of consensus, especially among deliberative democrats. Next we look at liberal pluralism, whose celebration of diversity is immediately qualified by recognition of the need to manage diversity - which often means consensus at some level. We pay special attention to Rawls's idea of an overlapping consensus, which turns out not to be up to the task of managing diversity of any depth. We move then to more radical critical pluralists (agonists and difference democrats), who scorn deliberative consensus and ambiguous liberal celebrations of diversity alike. However, even critical pluralists turn out to require some test for the substance of contributions to political debate that opens the door to a meta-consensus concerning this substance. In this tour we find no adequate resolution of the tension between pluralism and consensus, but we do find a number of pointers to what such a resolution would require. We build upon these to develop some ideas about simple pluralism combined with consensus at the meta level.

\section{Arguments for Consensus}

The appeal of consensus goes back to Rousseau; it is the obvious way for individuals to remain free while being subject to collective decisions, for then those decisions embody only the desires of free people. To many contemporary political theorists, consensus remains the gold standard of political justification, and this is especially true for deliberative democrats. The deliberative turn in democratic theory meant that the legitimacy of political arrangements came to be seen in terms of the right or capacity of those subject to a collective decision to participate in deliberation about its content. To some deliberative democrats (e.g., Manin 1987), deliberation was

John S. Dryzek is Professor of Social and Political Theory, Political Science Programme, Research School of Social Sciences, The Australian National University, Canberra, ACT Australia 0200 (John.Dryzek@anu.edu.au). Simon Niemeyer is an ARC Postdoctoral Research Fellow, Political Science Programme, Research School of Social Sciences, The Australian National University, Canberra, ACT, Australia 0200 (Simon.Niemeyer@anu.edu.au).

This research was supported by Australian Research Council Discovery Grant DP0558573. Previous versions of this article were presented to the 2003 Annual Conference of the American Political Science Association, the Political Theory Seminar at the London School of Economics, and the Social and Political Theory Program at Australian National University. For comments and criticism we thank Robert Goodin, Andrew Knops, Christian List, Eric MacGilvray, and the anonymous referees.

American Journal of Political Science, Vol. 50, No. 3, July 2006, Pp. 634-649 
just a prelude to voting and majority rule, though legitimacy was sought in the procedures of the prior deliberation, not in voting itself. Others scorned the thin "aggregative" model of democracy to which voting seemed to belong, and instead endorsed consensus as an alternative (e.g., Elster 1986a), conferring legitimacy to the extent it is informed, uncoerced, and reflective. As Cohen put it in his classic statement, "Outcomes are democratically legitimate if and only if they could be the object of free and reasoned agreement among equals" $(1989,22)$. Critics had no difficulty in identifying deliberative democracy with the pursuit of consensus; as Young put it, "The goal of deliberation is to arrive at consensus" $(1996,122)$.

Habermas (1996) acknowledges political pluralism but retains consensus as an ideal for public agreement on the procedures of his "two track" deliberative democracy. In addition, "The democratic principle states that only those statutes may claim legitimacy that can meet with the assent of all citizens in a discursive process of legislation that in turn has been legally constituted" (Habermas 1996, 110). Bohman interprets this as a "procedural ideal for laws: the legitimacy of laws depends on the democratic character of the legislative process that makes possible a consensus of all citizens" (1998, 402).

\section{Liberal Pluralism}

Pluralism too has been widely celebrated as a cornerstone of democracy because it features multiple centers of power, counters authoritarianism, and provides the basic grist for political debate. Robert Dahl and David Truman located pluralism in interest group politics and placed it at the heart of their explanation and evaluation of American liberal democracy. Interest group pluralism is an easy target for deliberative democrats attuned to consensus because the politically weighted sum of private interests so clearly does not add up to the public interest.

Liberal justifications for pluralism are not necessarily tied to interest group politics. For John Stuart Mill, political disagreement was instrumental in the development of competent individuals because only in disagreement could individuals come to know the basis for their own positions. The contemporary theory of liberal pluralism owes much to Berlin (1969), who stressed the plurality and incommensurability of basic values. For Berlin, "negative liberty" is conducive to the flourishing of diversity and judgment across different values (Gray 1996). For Galston $(2002,4)$, pluralism is part of the basic justification of liberalism. Diversity for Galston is an "intrinsic value," not a problem to be overcome or managed as it is in the very different liberalism of Rawls (Galston 2002, 27). Popper (1966) justifies liberal pluralism in terms of political rationality: effective policy making consists of cautious interventions that are tested and criticized from a variety of directions so that their benefits and flaws may be revealed, and policy improved.

Liberal arguments do not end neatly with celebration of diversity because diversity begs the question of how conflict is to be managed. The Madisonian answer is that constitutions should be designed to channel conflict across "factions" in productive direction. Dahl and Truman posited unproblematic background consensus on the rules of the political game and received criticism for their failure to recognize inbuilt biases to the rich and powerful. Gray (1996) favors a modus vivendi across conflicting values. Galston follows Berlin in stressing pragmatic judgment in particular contexts. Aside from constitutional constraint, Galston also highlights "minimal conditions of public order" and "ethical presumption" in curbing pluralism's "centrifugal" tendencies (2002, 6578). "Ethical presumption" consists of basic principles (e.g., never lie, do not target noncombatants in wartime) that may be overridden in extraordinary circumstances. Galston draws comfort from his experience in government, where, faced with diverse views coming from different departments, "I found it remarkable that we could reach deliberative closure in the face of this heterogeneity" (7).

The conditions of dialogue in which reconciliation across competing values is sought matter enormously, and in Galston's hands they have a very substantively liberal tinge to them. They include "clear and stable property relations, the rule of law, a public authority with the capacity to enforce the law" (65), "a suitably regulated market economy, a basic level of social provision" (66). Liberal pluralism of the Berlin-Galston type is itself a pragmatic compromise that makes some liberals and some pluralists uneasy. Some liberals veer away from pluralism: most prominent among them is John Rawls. Some pluralists veer away from liberalism: notably, agonists and difference democrats. Let us examine these two approaches.

\section{Rawls's Overlapping Consensus}

One of the more high-profile attempts to reconcile pluralism and consensus is Rawls's (1993) "overlapping consensus" on the basic institutions of society; once this structure is established, pluralism can hold in particular policy issues. Rawls starts from the ineliminable plurality of "comprehensive doctrines" in contemporary societies. 
These doctrines might be religious, ideological, or moral, but their differences are incapable of erasure (of the sort Rawls himself once sought in A Theory of Justice). How, then, are their partisans to agree on the basic structure of society? Rawls rejects a modus vivendi as a temporary resolution sensitive to the relative power of supporters of different doctrines, which as that power shifts, is likely to come undone. For Rawls, modus vivendi involves a compromise based on whatever reasons seem expedient to each side. Real-world examples would include consociational democracies as characterized by Lijphart (1977).

Rawls argues that an overlapping consensus must be supported from each comprehensive doctrine by moral reasons, ${ }^{1}$ yet "the reasonable doctrines endorse the political conception [i.e., the principles of justice], each from its own point of view" (Rawls 1993, 134). Waldron says that the overlapping consensus is "acceptable on moral grounds to the adherents of $\mathrm{C} 1 \ldots \mathrm{C} 2$, and so on. The grounds of course would not be the same in each case" $(2004,95)$. It is worth quoting Waldron's supporting example at length:

... the proposition that religious toleration is required as a matter of justice may be affirmed by Christians on Lockean grounds having to do with each person's individualized responsibility to God for his own religious beliefs, by secular Lockeans on the grounds of unamenability of belief to coercion, by Kantians on the grounds of the high ethical importance accorded to autonomy, by followers of John Stuart Mill on the basis of the importance of individuality and the free interplay of ideas, and so on. (95-6)

The problem is that the "so on" will not go very far. Lockean protestants, secular Lockeans, Kantians, and Millians are all species of liberal, and consent to the liberal principle of religious toleration for essentially liberal individualist reasons. Even within this restricted range, Waldron believes the kind of toleration reached by the four routes will actually be different, and back different courses of action precisely when the principle of toleration is needed to resolve key disputes (96). This suggests overlapping consensus is stronger to the degree different doctrines muster similar reasons for subscribing to it. At an extreme, to make a truly secure overlapping consensus,

\footnotetext{
${ }^{1}$ Rawls is not proposing meta-consensus; rather it is overlapping consensus at the simple level he seeks. As List puts it, participants "agree at a substantive level, albeit with respect to a restricted realm of issues, without necessarily agreeing on any meta-theoretical foundations for their substantive agreement" $(2002,77)$.
}

they will be able to muster the same moral reasons. And these reasons ought to be basic ones for each doctrine. This drive to uniformity warrants Mouffe's skepticism of what Rawls calls a reasonable pluralism. For Rawls defines a "reasonable" individual as someone committed to basic liberal principles $(1996,249)$. Thus it is no surprise that these individuals endorse a liberal conception of justice in their overlapping consensus. Setting aside any specifically liberal content of the overlapping consensus and focusing on its formal structure, the general point is that any overlapping consensus requires agreement on the priority of some set of substantive values.

The limits of Rawlsian overlapping consensus can be clarified through reference to MacIntyre's (1984) suggestion that theorists' worries about the centrifugal effects of conflicting values may often be misplaced. MacIntyre (1984, 500-501) points to examples where ethicists who disagree on fundamental principles of morality (pure ethics) often agree when it comes to practical issues (applied ethics), as context-specific reasoning overcomes abstract differences. But mainly he is talking about differences among ethicists in Western societies, trivial in comparison to some of the deeper divisions in the contemporary world. For MacIntyre, part of the key to resolution is a shared tradition, given his belief that conceptions of justice and rationality are tradition specific (MacIntyre 1988). Liberalism for MacIntyre is one such traditionand most ethicists are liberals of one kind or another. So for all their differences, MacIntyre and Rawls end up with the same problem: neither offers a general solution here for the management of pluralism because a shared tradition such as liberalism or a shared set of values may not always be available. ${ }^{2}$

\section{Critical Pluralism and Difference Democracy}

A more radical contemporary pluralism is suspicious of liberal and communitarian devices for reconciling difference. Such a critical pluralism is associated with agonists such as Connolly (1991), Honig (1993), and Mouffe (2000), and difference democrats such as Young (2000). As Honig puts it, "Difference is just another word for what used to be called pluralism" $(1996,60)$. Critical pluralists resemble liberals in that they begin from the variety of ways it is possible to experience the world, but stress

\footnotetext{
${ }^{2}$ If it is not, then MacIntyre (1988) believes reasoned discourse across traditions can still take place when one tradition reaches a crisis (in its own terms) that moves its adherents to look for resources for its resolution in other traditions.
} 
that the experiences and perspectives of marginalized and oppressed groups are likely to be very different from dominant groups. They also have a strong suspicion of liberal theory that looks neutral but in practice supports and serves the powerful.

Difference democrats are hostile to consensus, partly because consensus decisionmaking (of the sort popular in 1970s radical groups) conceals informal oppression under the guise of concern for all by disallowing dissent (Zablocki 1980). But the real target is political theory that deploys consensus, especially deliberative and liberal theory. Young $(1996,125-26)$ argues that the appeals to unity and the common good that deliberative theorists under sway of the consensus ideal stress as the proper forms of political communication can often be oppressive. For deliberation so oriented all too easily equates the common good with the interests of the more powerful, thus sidelining legitimate concerns of the marginalized. Asking the underprivileged to set aside their particularistic concerns also means marginalizing their favored forms of expression, especially the telling of personal stories (Young 1996, 126). ${ }^{3}$ Speaking for an agonistic conception of democracy (to which Young also subscribes; 2000, 49-51), Mouffe states:

To negate the ineradicable character of antagonism and aim at a universal rational consensusthat is the real threat to democracy. Indeed, this can lead to violence being unrecognized and hidden behind appeals to "rationality," as is often the case in liberal thinking. (1996, 248)

Mouffe is a radical pluralist: "By pluralism I mean the end of a substantive idea of the good life" $(1996,246)$. But neither Mouffe nor Young want to abolish communication in the name of pluralism and difference; much of their work advocates sustained attention to communication. Mouffe also cautions against uncritical celebration of difference, for some differences imply "subordination and should therefore be challenged by a radical democratic politics" $(1996,247)$. Mouffe raises the question of the terms in which engagement across difference might proceed. Participants should ideally accept that the positions of others are legitimate, though not as a result of being persuaded in argument. Instead, it is a matter of being open to conversion due to adoption of a particular kind of democratic attitude that converts antagonism into agonism, fighting into critical engagement, enemies into adversaries who are treated with respect. Respect here is not

${ }^{3}$ Correspondingly, Young $(1996,123)$ believes that deliberation privileges argument oriented to winning, a form of expression suited to well-educated and well-off men. just (liberal) toleration, but positive validation of the position of others. For Young, a communicative democracy would be composed of people showing "equal respect," under "procedural rules of fair discussion and decisionmaking" $(1996,126)$. Schlosberg speaks of "agonistic respect" as "a critical pluralist ethos" $(1999,70)$.

Mouffe and Young both want pluralism to be regulated by a particular kind of attitude, be it respectful, agonistic, or even in Young's $(2000,16-51)$ case reasonable. Thus neither proposes unregulated pluralism as an alternative to (deliberative) consensus. This regulation cannot be just procedural, for that would imply "anything goes" in terms of the substance of positions. Recall that Mouffe rejects differences that imply subordination. Agonistic ideals demand judgments about what is worthy of respect and what is not. Connolly $(1991,211)$ worries about dogmatic assertions and denials of identity that fuel existential resentments that would have to be changed to make agonism possible. Young seeks "transformation of private, self-regarding desires into public appeals to justice" (2000, 51). Thus for Mouffe, Connolly, and Young alike, regulative principles for democratic communication are not just attitudinal or procedural; they also refer to the substance of the kinds of claims that are worthy of respect. These authors would not want to legislate substance and are suspicious of the content of any alleged consensus. But in retreating from "anything goes" relativism, they need principles to regulate the substance of what rightfully belongs in democratic debate.

Whatever their differences, all the schools of thought canvassed so far agree that pluralism is a potentially problematic issue as well as a value. All see communication across difference as key to resolution (except for Rawlsian liberals who want to legislate basic structure for the resolution of differences). What we propose in the rest of this article is a way of thinking about what such communication ought to try to achieve, doing our best not to smuggle in substantive political commitments. We do not expect this approach to be accepted by all those we have discussed, but we try to make it sensitive to the issues they have raised. The balance will involve pluralism in values, beliefs, and preferences in the context of meta-consensus on one or more of these three aspects, though both the content of meta-consensus and the way it is produced require critical scrutiny.

\section{A Typology of Consensus}

Consensus first needs to be broken down into its constituents based on the processes at work when individuals arrive at policy preferences. Some conceptions of 


\section{TABLE 1 Types of Consensus}

\begin{tabular}{lccc}
\hline & \multicolumn{3}{c}{ Element of Preference Construction } \\
\cline { 2 - 4 } Type of Consensus & Value & Belief & Expressed Preference \\
\hline \multirow{2}{*}{ Meta-Counterpart } & $\begin{array}{c}\text { (Agreement on the values } \\
\text { that should predominate) } \\
\text { Recognition of legitimacy of } \\
\text { disputed values }\end{array}$ & $\begin{array}{c}\text { Epistemic consensus } \\
\text { (Agreement on belief about } \\
\text { the impact of a policy) } \\
\text { Acceptance of credibility of } \\
\text { disputed beliefs }\end{array}$ & $\begin{array}{c}\text { Preference consensus } \\
\text { (Agreement on expressed } \\
\text { preference for a policy) } \\
\text { Agreement on the nature of } \\
\text { disputed choices }\end{array}$ \\
\hline
\end{tabular}

consensus proceed in terms of preference aggregation, such that consensus connotes agreement on what is to be done. However, consensus can also refer to the values and beliefs that help explain particular preferences. Preferences, values, and beliefs alike can be influenced by both decision procedures and political contexts.

In this light, building upon Elster $(1998,100)$, three kinds of consensus can be identified (see Table 1). The first, normative consensus (or what Rescher 1993 calls axiological consensus) refers to agreement regarding values driving the decision process. The second, epistemic consensus, refers to the judgmental aspect of preference formation, agreement about how particular actions map onto values in cause and effect terms. The third type, preference consensus, pertains to the degree of agreement about what should be done. (This is where, for example, social choice theory operates. ${ }^{4}$ ) Universal consensus in Femia's $(1996,368)$ terms would occur with agreement in all three aspects-normative, epistemic and, consequently, preference. Each of these three kinds of consensus has a "meta" counterpart, which we will describe in the next section.

The three types of consensus can be illustrated by a particular policy issue. Our example concerns the Bloomfield Track, a road constructed through World Heritage Rainforest in the tropical far north of Australia, and the future of which remains a matter of public contention. ${ }^{5}$ Three groups defined on the basis of their underlying point of view on this issue are shown in the first column of Table 2 . The second column reflects the normative value that each group holds most dear; the third column the beliefs about what means are most likely to satisfy that end. The final column shows the expressed preference that follows from the combination of values and beliefs.

\footnotetext{
${ }^{4}$ We use the concept of "preference" as is standard in economicsthat is, as a ranking of alternatives by an individual.

${ }^{5}$ The Track ostensibly services an isolated community, but is more commonly used by tourists. For an extended description, see Niemeyer (2002, Chapter 6).
}

The first group, the "Pragmatists," believes that the most important consideration is the need of the local community for access (particularly in the absence of clear evidence of environmental damage). They believe that the road best serves this purpose. This leads them to conclude that the best option is to keep the road open. By contrast, "Preservationists," who give primacy to potential ecological impacts, believe that the road is detrimental in these terms. They accordingly prefer closure. A third group, "Optimists," similarly places a premium on environmental values, but also recognizes community interests. The potential dissonance of this normative position is reduced by a belief that the road can actually benefit both these values-for example, if tourism can increase the profile of the region, promoting more widespread concern for its environmental value.

An examination of Table 2 shows there is no universal consensus across all three groups, but there is agreement across elements of their positions. There are normative overlaps among the groups (Optimism with Preservation on the dominance of environmental concern, Optimism with Pragmatism on recognition of the community dimension). At the epistemic level there is dissensus across the three groups, which is why it is possible for agreement on values to coincide with disagreement on policy preference (Preservationists and Optimists). The converse is also true: Pragmatists and Optimists disagree at the normative level but have similar preferences. The latter is an example of what Sunstein (1995) calls an incompletely theorized agreement. Preference consensus unites the Pragmatists and Optimists against the Preservationists.

\section{A Typology of Meta-Consensus}

We now develop and highlight the idea that normative, epistemic, and preference consensus all have a "meta" counterpart (see Table 1), which can help structure the 
TABle 2 Preference Formation, The Bloomfield Track

\begin{tabular}{|c|c|c|c|}
\hline & $\begin{array}{c}\text { Value } \\
\text { Normative Level }\end{array}$ & $\begin{array}{c}\text { Belief } \\
\text { Epistemic Level }\end{array}$ & $\begin{array}{c}\text { Expressed } \\
\text { Preference } \\
\text { Preference Level }\end{array}$ \\
\hline Pragmatists & $\begin{array}{l}\text { Needs of community most } \\
\text { important }\end{array}$ & Road will benefit the community & Keep road \\
\hline Preservationists & $\begin{array}{l}\text { Needs of environment most } \\
\text { important }\end{array}$ & $\begin{array}{l}\text { Road will negatively impact the } \\
\text { environment }\end{array}$ & Close road \\
\hline Optimists & $\begin{array}{l}\text { Needs of environment most } \\
\text { important (community matters } \\
\text { too) }\end{array}$ & Road will benefit the environment & Keep road \\
\hline
\end{tabular}

process of deliberation. Normative meta-consensus exists to the extent that there is agreement on recognition of the legitimacy of a value, though not extending to agreement on which of two or more values ought to receive priority in a given decision. The recognition that defines normative meta-consensus is facilitated to the degree that the values in question are not positioned in a necessary zerosum trade-off, though this perception is not crucial, and will not always be available. Normative meta-consensus is consistent with the sort of recognition one could expect under Habermasian conditions of communicative rationality, which does not require normative uniformity at the substantive level, only recognition of the "generalizable" status of norms, which may end up informing different policy positions (Dryzek 1990, 17). The value pluralism of liberals such as Berlin (1969) and Galston (2002) must always be discriminating in the values it allows, so requiring normative meta-consensus (though they do not use this terminology). However normative meta-consensus need not be tied to Galston's prescriptive and substantively liberal tests for admissible values. Normative metaconsensus can be forged in pragmatic and contextual fashion as suggested by Berlin, though this begs a number of questions about the conditions of any such process, which we will address later. Normative meta-consensus differs from Rawlsian overlapping consensus because its recognition of values does not depend on their having counterparts in other "comprehensive doctrines."

In the example in Table 2 there are two normative dimensions, pertaining respectively to community and environmental interests. Normative meta-consensus extends across the three groups. While environmental issues are often portrayed in terms of a clash between two kinds of values, most individuals are actually likely to endorse both sets of values (cf. Rokeach 1979). That individuals privilege community needs over environment is not to say that they are hostile to environmental concern, and vice versa. It is just as unlikely that individuals given unconstrained choices would support environmental degradation as it would be for them to want the Bloomfield community to be worse off. In addition, individuals may have "multiple selves" at the normative level (Elster 1986b), the analog of normative pluralism among groups, with different "selves" invoked by different circumstances. Normative meta-consensus would mean different sides (and different selves) should end up agreeing that the others have legitimate values. We note in passing that adversarial processes (such as Anglo-American legal systems) may weaken normative meta-consensus if they frame issues in ways that induce advocates to denigrate the legitimacy of the values of the other side.

One of the more robust findings of the psychology literature on values is that at the abstract level there is a high degree of agreement on the legitimacy of basic values (Rokeach 1979). Individuals differ mainly on the relative priority of values, and how they apply in particular cases. In our terminology, normative meta-consensus is pervasive (and can indeed be found in our Bloomfield Track case). Our results are consistent with the psychology literature on this point: no normative positions held by participants were hostile to environmental or community values before or after deliberation. However, prior to their deliberation, community and environmental values were widely perceived to exist in zero-sum relationship, such that a trade-off would need to be made. After deliberation, appreciation of the potential complementarity of community and environmental values had grown. If the psychology literature is correct, one of the main tasks of deliberation could be to uncover existing normative metaconsensus obscured by the strategic actions of partisans who try to delegitimate the values held by their opponents. For example, former U.S. Secretary of the Interior James 
Watt once tried to distinguish between Americans and environmentalists, implying strong environmental values had no place in the normative meta-consensus of American society. Less strategically inept moves with similar intention are made against those whose commitment to human rights can be made to look unpatriotic in the context of the "war on terror." This kind of strategic positioning is very different from the kind of problem that preoccupies agonists and difference democrats, which features a visceral clash of identities that often find validation in denial of the identity of others.

Our Bloomfield Track case does not feature such deep difference in values and identities, so let us introduce a case that has these problematic features. The case is reported by Forester (1999) and Hughes (1999) and concerns a dialogue on HIV-AIDS policy in Colorado designed to produce advice for the state government. The dialogue involved 60-70 participants in a series of monthly then weekly meetings facilitated by a mediator (Hughes). Participants were selected to represent demographic diversity as well as the key interests active on this issue. They included gay activists (including members of ACT-UP), people with AIDS, and fundamentalist Christians active in anti-gay rights campaigns. Conflicting values were in this case basic to the identity of gay activists and fundamentalists in particular (Forester 1999, 462). The fact that the fundamentalists were active in anti-gay rights campaigns-especially a 1992 statewide ballot initiative that passed, prohibiting state and local governments in Colorado from explicitly protecting civil rights for gays and lesbians-showed that their identity in particular required validation through denial of gay identity. Thus the initial conditions were deep normative meta-dissensus and an absence of recognition.

The deep difference between the two sides was crystallized in a statement by a gay activist to the forum that "There is a need to shift the discussion of AIDS in Colorado from a moral issue to a public health issue, and I refuse to participate in moving this plan forward until we wrestle with that" (quoted in Hughes 1999, 1020). To the fundamentalist Christians the issue was entirely moral: "If it isn't a moral issue, people will continue to behave in ways that put them in danger" (quoted in Hughes 1999, 1021). Each side rejected the way the issue was framed by the other.

As the dialogue proceeded, the two sides could, however, realize that they were not going to change the values of the other side. Their written agreement contained an explicit statement of the participants' recognition of a normative meta-consensus: "For communities that include members with a range of moral perspectives, HIV prevention methods need to be appropriate to that range of moral perspectives" (Hughes 1999, 1025). From the outset the participants had a shared interest in reducing risk, suffering, and death, ingredients it might seem for a Rawlsian overlapping consensus. But any shared interests along these lines did not move them beyond impasse; only a normative meta-consensus following prolonged confrontation with the other side and its values could do that. The specific measures to which each side consented were not components of an overlapping consensus. These measures included moral education in schools and sexually explicit material targeted at the gay community, which remained objectionable to gay activists and fundamentalist Christians, respectively.

Epistemic meta-consensus is agreement on the credibility of disputed beliefs, and on their relevance to the norms that define the issue at hand. (Beliefs may be credible but irrelevant.) Credibility here means that it is accepted by others as reasonable to hold the belief in question. Epistemic meta-consensus can therefore accommodate the multiplicity of perspectives required by epistemic arguments for the political rationality of pluralism (for example, Popper 1966). Complexity of a phenomenon and associated uncertainty can preclude definitive choice across competing explanations and their associated theories or perspectives. This is recognized by Herbert Simon in his description of bounded rationality. Competing explanations may then coexist. This coexistence can apply not just in politics, but also in natural science: for example, explanations of the behavior of light as both a wave and a particle in optical physics.

The opposite of meta-consensus occurs when scientific paradigms compete (on Kuhn's 1970 account). This kind of epistemic meta-dissensus can also be seen in some environmental issues, with genetic modification a particularly good example of a large gap between the kinds of knowledge claims regarded as legitimate by proponents and opponents of the technology. Yet there are situations where competing epistemic claims can both be accepted as valid. For example, local residents' experiences of the ill-effects of toxic pollution could be regarded as just as valid as the epidemiological studies that typically do not confirm these experiences (Tesh 2000). Any fault may lie in the demanding statistical requirements of epidemiological proof, as much as in residents' perceptions. This toxic pollution example shows that belief systems and not just isolated beliefs can enter an epistemic meta-consensus; these systems highlight, respectively, statistical analysis and personal experience. Sometimes the differences between such systems are deep; consider for example differences between scientific and fundamentalist religious worldviews. The identification of epistemic meta-consensus is especially challenging in such cases. 
Preference meta-consensus consists of agreement on the nature of disputed choices across alternatives and has two aspects. The first concerns the range of alternatives considered acceptable. For example, Dworkin (1977) wants to rule out "external" preferences that an individual has for harm to others. Goodin (1986) speaks of "laundering" preferences before they are taken into account in collective decision making. Most theorists who have contemplated the issue want the acceptable range to be limited by constitutional or legal means-so, for example, the German constitution rules out the option of choosing an extreme right party. However, deliberation itself could produce consensus on the range of acceptable alternatives.

The second aspect of preference meta-consensus concerns the validity of different ways that choices across alternatives can be structured. Several types of structure are available. List (2002) has suggested one such type, in terms of agreement on a single important issue-dimension along which preferences are to be structured. ${ }^{6}$ This is demonstrated in Figure 1 using the Bloomfield Track case study. Five policy alternatives can be ordered according to the degree of access they would permit to the Bloomfield region. Bitumenization (sealing) leads to greatest access for vehicles; closure the least access. Intermediate policies of upgrading by covering with gravel, stabilizing steep slopes to reduce soil slippage, or leaving the road as a four-wheel-drive track each give decreasing degrees of access. If there is agreement that degree of access is the most important dimension, policy preferences should be "single peaked" along this dimension. Preference metaconsensus on this particular dimension would form if there is epistemic meta-consensus that the condition of the Track is the prime causal factor determining benefits to the community and/or damage to the environment, which in turn are recognized as the key values in a normative meta-consensus. Figure 1 shows four cases of singlepeaked policy preference rankings along this dimension, illustrated by the solid lines. The broken line is not single peaked.

According to List (2002), agreement at the metalevel exists to the degree preference orderings are single peaked on a dimension that is recognized as central by participants (because nonsingle-peakedness can only be explained by the individuals in question having their preference ordering determined along a different but related dimension).

\footnotetext{
${ }^{6}$ The "preference" is added by us; List refers simply to metaconsensus and does not recognize our normative and epistemic categories, or the aspect of preference meta-consensus that refers to the acceptable range of alternatives, or forms of structure other than single-peakedness on an agreed dimension.
}

\section{FIGURE 1 Single-Peaked Preference Orderings of Bloomfield Track Policies}

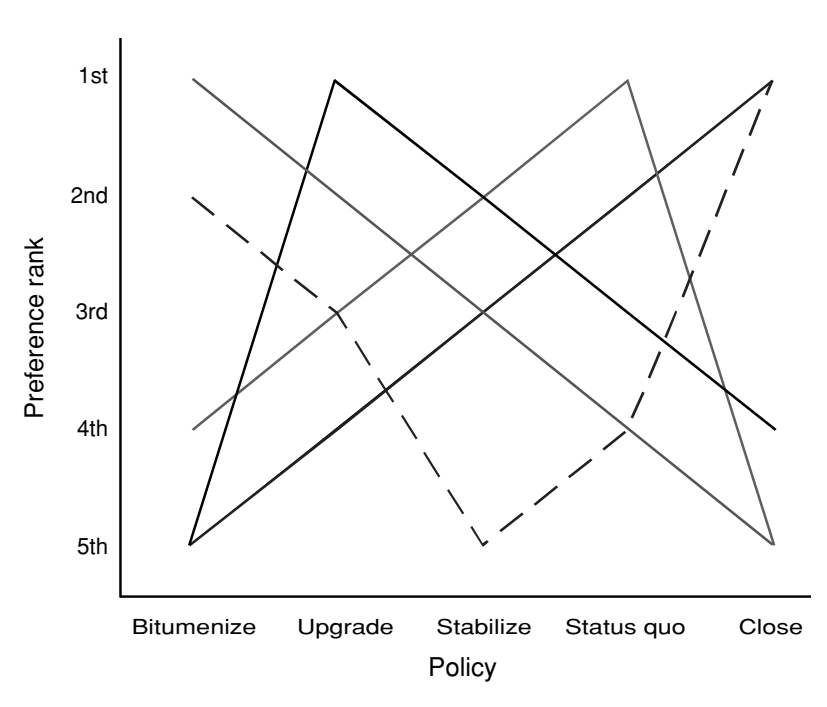

However, single-peakedness is not the only type of structuration of choices. Say, for example, that there is normative meta-consensus on the Bloomfield Track that environmental and community values are the important considerations, and epistemic consensus that the mere presence of the road will continually increase environmental damage by opening up new areas for development. Preferences may then be structured not along degree of access, but simply between closure and all other options where the road remains open. This sort of preference meta-consensus involving option reduction became observable and important at a key point in deliberation on this issue. Option reduction has the effect of restricting the number of alternatives that pass the relevance test and so formally resembles restriction on the basis of acceptability (the first kind of preference meta-consensus we identified).

Respect for Persons as a Prelude to Meta-Consensus? "Respect" can refer not only to the values, preferences, and beliefs that individuals hold, but also to their personhood. Arguably recognition of others as comembers of a moral community facilitates dialogue that generates meta-consensus. However, respect for persons may be beside the point when it comes to generating metaconsensus. Christians, for example, may "hate the sin and love the sinner"- but so long as the sin is still hated, it is outside the boundaries of any meta-consensus. Respect for the moral standing of different others may prevent violence against them, but it is still consistent with a refusal to countenance engagement with their (sinful) views (and so is not like the agonistic respect discussed 
earlier). Correspondingly, respect for persons is unnecessary if respect for what they are saying can be secured. In the Colorado HIV-AIDS case, progress could be made once each side recognized the legitimacy of the values of the other side as they might have to enter public policy consideration-while not recognizing the legitimacy of the identity of the others and (on the fundamentalist side) still believing that gays and lesbians should be denied public policy protection of their rights as a matter of state policy. Any connection between respect for persons and the presence of meta-consensus is contingent, likely to vary substantially between different cases.

\section{Meta-Consensus as the Key?}

Our taxonomy of modes of consensus and metaconsensus suggests one way of reconciling opposing ideals of consensus and pluralism. This reconciliation would involve normative, epistemic, and preference pluralism at the simple level (except in rare cases where simple consensus is unproblematic), together with consensus on one or more of these three aspects at the meta level. In this section we will develop the positive side of this resolution, before moving to its limits. Pointing to the virtues of meta-consensus does not imply that any meta-consensus is defensible, or that it should strive to cover (say) Nazi values, crackpot science, and preferences for the suffering of others. Any meta-consensus is characterized by exclusions as well as inclusions.

The first argument to be made for this resolution is that at the simple level, consensus of any of our three types is likely to be elusive in any society with any degree of pluralism. Now, processes such as mediation (where parties to a dispute sit down under the auspices of a neutral third party and seek a resolution receiving the consent of all sides) often produce what at first looks like preference consensus in the sense of agreement about what is to be done. But such agreement will often represent only what each party can accept in comparison to what would happen otherwise. Indeed, partisans will generally enter into such a process only if they fear the outcome that will prevail otherwise. So in mediation over a development dispute, environmentalists and community groups may accept an outcome of "responsible development" if they think the likely alternative is irresponsible development. This acceptance does not mean that responsible development is now their first choice. Such an outcome can be achieved with continuing dissensus across environmentalists and developers at the normative, epistemic, and indeed preference levels. Mediation involves construction of a normative meta-consensus across initially hostile partisans, which then facilitates a search for mutually accept- able outcomes that are better than any mere compromise between the initial positions of partisans.

Meta-consensus makes fewer demands upon partisans than does simple consensus and so ought to be available more often. In particular, it can still be available when partisans continue to disagree profoundly about what should be done. But meta-consensus will not always be available, and it may take hard work to discover or create. Sometimes partisans will prefer to continue to fight with every means at their disposal. Yet because in comparison with simple consensus it makes fewer demands on partisans to compromise their first-order values, beliefs, and preferences, the achievement of meta-consensus is less dependent on the motivations of partisans to seek agreement. Even when disagreement can be resolved only by voting, meta-consensus can facilitate the generation of better outcomes-as we will show in a discussion of the benefits of preference meta-consensus.

Any rarity or elusiveness of simple consensus is not in the end a decisive argument against its pursuit. As we said at the outset, consensus of any kind can be a matter of degree. In the case of a citizen's jury convened to deliberate the Bloomfield Track issue, ${ }^{7}$ the jury process did increase preference consensus. At the end of the jury, seven of twelve jurors favored closing the track, while at the outset of the process none of the five options was the first choice of more than four jurors. (So the product of deliberation was not a compromise, but rather a shift to one extreme. The Condorcet winner changed from stabilization of the existing condition of the track to closing the track. ${ }^{8}$ ) Yet preference dissensus remained at the end of the process.

A more telling argument against an exclusive focus on simple consensus is that its content is hard to evaluate, except through reference to the procedure that produces it. So it is straightforward to condemn a procedure that involves threats and manipulation or to praise procedures that involve relatively uncoerced dialogue. Though even here, warning bells are sounded by difference democrats who dispute the possibility of any neutral rules of debate, as well as by those such as Kuran (1998) and Femia (1996), who see conformity pressures at work in deliberation.

\section{On Behalf of Normative Meta-Consensus}

Normative meta-consensus implies reciprocal understanding and recognition of the legitimacy of the values held by other participants in political interaction. Deliberative democrats who have taken deep moral disagreement seriously, such as Gutmann and Thompson, prize

\footnotetext{
${ }^{7}$ The jury is more extensively reported in Niemeyer $(2002,2004)$.

${ }^{8} \mathrm{~A}$ Condorcet winner by definition beats all others in pairwise comparisons.
} 
reciprocity: "the capacity to seek fair terms of cooperation for their own sake" $(1996,52-53)$. This means that citizens must provide reasons in terms that those with whom they disagree can accept - terms that go beyond their own particular interests in order to connect them with more general moral principles. In constructing justifications for their positions along these lines, individuals would in our language construct a normative meta-consensus. Gutmann and Thompson are excessively prescriptive in specifying the content of normative meta-consensus as general moral principles. They lay out what their ideals of reasonableness require in the substantive resolution of particular policy disputes such as that over abortion. Thus their normative meta-consensus is overspecified. From our point of view, normative meta-consensus not only promotes the ability of different groups in a plural society to coexist in civility and recognize their joint membership of a democratic polity, but also the likelihood that they will engage in a creative search for outcomes that respect the basic values of all parties, however different these values remain. Of course, this search will not necessarily prove successful, but collective choice does become more tractable.

We can further clarify the role of normative metaconsensus in making collective decision more tractable by looking more closely at the practical literature on conflict resolution concerned with mediation and "consensus building"-essentially the same thing. Such approaches seek agreement across parties to a dispute, but not consensus in the sense usually used in political theory. In mediation and related approaches, agreement is sought on actions to be taken. Under the auspices of a neutral facilitator or mediator, participants strive for unanimity but do not necessarily achieve it. The agreement represents a course of action participants can live with; it is not necessarily their first preference, but they realize it is better than the best they are likely to get in the absence of any agreement. The agreement receives their reflective assent, partly in the knowledge that their concerns have been recognized and addressed, even if they are not shared by other participants. These approaches have been applied to disputes in many areas of life (environment and development, workplace disputes, divorce, planning, etc.). Their advocates point to the stability, efficiency, and fairness of the outcomes produced-especially in comparison with more adversarial legal processes.

Mediation and consensus building resemble the "incompletely theorized agreements" of which Sunstein (1995) speaks. Part of their lack of theorization is the absence of any attempt to ground them in shared principles, so actors can consent for completely different reasons. Less ambiguously than either MacIntyre or Rawls,
Sunstein allows that agreements may be endorsed for truly different reasons from different sides. But beyond pointing to a practical possibility that may sometimes be available, Sunstein offers no general principles for political dialogue. Rawls would presumably object that an incompletely theorized agreement has no necessary moral content or backing from the moral principles of different partisans and so provides an insecure basis for political arrangements in a plural society. Advocates of practical consensus building and mediation approaches such as Susskind, McKearnan, and Larmer (1999) would say that the lessons of experience contradict this theoretical worry, that such agreements do have staying power. But the whole point of consensus building and mediation is that such agreements require hard work on the part of both participants and the facilitator; they are not to be expected in the ordinary give and take of politics, still less in the legal system. Practitioners, advocates, and observers of these processes stress that they cannot be understood in strategic, game-theoretic terms. These processes are not oriented to simple compromise of the sort that could be achieved by strategic bargaining. Instead, the target is an outcome that is more responsive to the concerns of both sides than any bargained compromise could be, which in turn requires creativity in joint problem solving. Interactions are governed by a set of principles that might (say) forbid ad hominem attacks, stereotyping of adversaries, making threats, concealing information, delaying tactics, or statement of a bargaining position. Mediators regard it as crucial that participants come to recognize the legitimacy of the normative position of their adversaries and are prepared to reflect upon their own positions. In our language, successful mediation requires construction of a normative meta-consensus.

Recognition of the legitimacy of the other's normative point of view is prized by critical pluralists such as Schlosberg (1999), postmodern theorists of identity and difference such as Connolly (1991), and agonists such as Mouffe (2000). All of these theorists are otherwise highly critical of any impetus toward consensus of the sort they associate with restrictive and excessively rationalistic notions of political deliberation. They can also lack much in the way of an orientation to collective decision, so the previous argument concerning normative metaconsensus's contribution to decision tractability will leave them cold. Still, normative meta-consensus can be consistent with the idea of "justice as recognition" that theorists of identity and difference promote. Mouffe allows that "pluralist democracy requires a certain amount of consensus" $(1999,756)$. This does not mean that difference democrats and critical pluralists would endorse any normative meta-consensus, and they would be alive 
to the degree to which any particular normative metaconsensus unjustly excludes particular values and those who subscribe to them. Normative meta-consensus might have to be treated as provisional and itself contestable. As Mouffe puts it, the "different and conflicting interpretations" of "ethico-political principles" means that "consensus is bound to be a 'conflictual consensus"' (1999, 756), with no recourse to general values of the sort that even Gutmann and Thompson would call upon to establish the content of normative meta-consensus. Mouffe emphasizes the continued contestability of all political values. While allowing that (in our language) normative meta-consensus is necessary for pluralist democratic communication, she believes its construction is inevitably political and so contestable. But however underspecified its content in Mouffe's theory, normative meta-consensus is required - the basic agonistic distinction between "enemies" and "adversaries" implies that the latter are welcomed into a normative meta-consensus, while the former are not. Underspecification may be fatal if we want democracy to be oriented to collective decision; but for agonists that is not the point of democracy, which is more about how to live together in open-ended conversation.

Our discussions of critical pluralism suggest the following tests, though as we have stressed, agonists would treat all as provisional and contestable. For critical pluralists, values are legitimate entrants into a normative metaconsensus to the degree they

1. are not dogmatic (Connolly);

2. are not fueled by resentment (Connolly);

3. do not deny the identity of others;

4. are not "private, self-regarding desires" (Young);

5. do not entail the subordination of others (Mouffe);

6. are not relativistic in a refusal to recognize a constitutive other (Mouffe); and

7. do not appeal to their own superior rationality (Mouffe).

These seven tests are quite demanding, and a normative meta-consensus that falls short may still be valuable. In the HIV-AIDS case we introduced earlier, the normative meta-consensus was relatively thin, referring only to recognition of "communities that include members with a range of moral perspectives" who should live together rather than seek to subordinate one another. While passing tests 2,5 , and 6 , this particular meta-consensus did not reach the depth suggested by tests $1,3,4$, and 7 .

We conclude that whatever the character of the issue at hand, some normative meta-consensus is desirable. This does not mean that any normative meta-consensus is defensible. Premature normative meta-consensus might blunt the force of moral crusades against (say) racial dis- crimination were activists to admit racist values into a meta-consensus. But even here efforts could be made to include some of the relevant values held by racists. Consider for example the frequent invocation by Dr. Martin Luther King, Jr. of the values embedded in the United States Declaration of Independence and Bill of Rights. These appeals were designed in part to remind white Southerners of their shared membership in a normative tradition within which claims for racial justice could then be processed peacefully. At issue here is not just the application of shared values to the particular case of African American civil rights, but also the legitimate range of specific human rights that can be justified through reference to the basic idea of a rights-based political system and thus form part of a defensible meta-consensus.

We can distinguish between three types of issues. First, there are those that involve clashes of identity in a divided society. The key here is production of a normative meta-consensus that remains contestable. Second, there are issues that involve deep moral conflicts. The key here is production of a stable normative meta-consensus. Third, there are issues that feature competing interests but no deep denials of identity or morality across participants. The key here is uncovering an existing normative metaconsensus that is obscured by the strategic machinations of partisans.

The HIV-AIDS case is an example of the second type of issue, and we showed earlier that fundamentalist Christians and gay activists could nevertheless construct a normative meta-consensus. The dialogue eventually produced agreement on a set of concrete policy measures. At the end of the process the two sides still had fundamental differences in values and identities; the normative meta-consensus was specific to the HIV-AIDS issue under discussion. After the agreement had been reached, a discussion about whether being gay was a lifestyle choice threatened to explode; at this point the mediator simply suggested that everyone go home (Hughes 1999, 1025). Thus there was no normative consensus, no conversion of attitude to the other as sought by agonists. But there was a normative meta-consensus across deep difference produced by deliberation that made possible joint problemsolving progress and a set of mutually acceptable policy recommendations. This example demonstrates that normative meta-consensus can be achieved much more easily than normative consensus.

\section{On Behalf of Epistemic Meta-Consensus}

Epistemic meta-consensus for its part could be desirable on the grounds of deliberative economy. That is, to the extent a set of beliefs is accepted as credible and 
relevant, there is an understanding of what the main issues are, and so no need to debate fundamentals each time a claim is made. A parallel with paradigms in scientific communities can be drawn here. A paradigm by definition features strong epistemic meta-consensus, releasing practitioners from the sheer amount of time and effort it takes to get beyond debating basic assumptions and first principles. Of course, nothing as strong as a paradigm will normally be available (or necessarily desirable) in a political context. Epistemic meta-consensus permits the pluralism at the simple level required for complex issues to be scrutinized from a number of directions in the search for creative solutions that respond to different facets of issues (see our earlier discussion of Popper's argument for the rationality of simple pluralism in policy making).

In effect, epistemic meta-consensus creates a "problem-solving public" in the sense of pragmatist philosophers such as John Dewey (1927). To return to our toxic pollution example, government officials wielding epidemiological studies and local residents reporting particular experiences would not be stuck in ridiculing the methodological basis of each others' claims, but instead devote energy to joint problem solving. This effort might, for example, involve deploying some version of the "precautionary principle" in environmental policy, which is designed to inform policy making in situations of substantial uncertainty about the content and magnitude of risks. Such an outcome would not be in any sense a mere compromise between the epistemic positions of the two sides that would involve an assessment of risks somewhere between that of the epidemiologists and local residents, but rather a wholly new way of looking at decision in the context of risk.

Yet some differences of belief might resist incorporation in an epistemic meta-consensus; for example, when religious groups that deny the validity of modern science as an article of faith confront scientists who deny the validity of knowledge claims grounded in faith. Even here the impasse could be transcended to the extent the two sides could recognize that their conflict is in part about values rather than beliefs. Some joint problem solving might then be possible under a normative meta-consensus, as our HIV-AIDS example suggests.

Epistemic meta-consensus can also be instrumental to the creation of both normative and preference metaconsensus. If an issue is characterized by competing interests (but no deep denials of identity or morality - the third type mentioned in the previous subsection), then normative meta-consensus is facilitated to the degree values are not positioned in a necessary zero-sum relationship. To illustrate, in our Bloomfield Track example, deliberation reduced the credibility of claims about community access benefits of the track, which in turn led the jurors to recognize that community and environmental values were not necessarily diametrically opposed. Deliberation also enhanced the credibility of (still disputed) claims about the flow-on effects of development in the rainforest resulting from any option which left the track open, leading to a preference meta-consensus that the real choice was between closing the track and all other options.

\section{On Behalf of Preference Meta-Consensus}

Preference meta-consensus is valuable because it makes social choice less vulnerable to arbitrariness, instability, and manipulation by clever strategists. The first type of preference meta-consensus we identified concerns the range of acceptable alternatives. In the language of Arrow's social choice theory, this kind of meta-consensus limits the capacity of individuals to manipulate outcomes by introducing irrelevant alternatives, as well as reducing the cognitive demands associated with multiple options. The second type of preference meta-consensus, concerning the validity of ways in which choices can be structured, operates to restrict the domain of admissible preference profiles (and would, for example, rule out the preference profile represented by the broken line in Figure 1), thus overcoming the problem that Arrow's "universal domain" condition causes for social choice. To the extent that the preferences of actors are single peaked along one dimension, the chances that there is a Condorcet winner across policy options-one that beats all others in pairwise comparisons - is increased (Knight and Johnson 1994, 282-83). And if there is a Condorcet winner, then the possibility of cycles across options disappears (Black 1948). It is the possibility of such cycles (where option A beats $B$ beats $C$ beats $A$ in simple majority voting) that leads Riker (1982) to conclude that there is no such thing as the will of the people, which reflects only the aggregation (voting) mechanism used to measure it. Clever strategists realize this, and so attempt to manipulate procedures (for example, the order in which votes are taken) to get their way.

We pointed out earlier that agreement on an issue dimension is not the only way choices can be structured. For example, in our Bloomfield Track case, structuration was eventually produced through meta-consensus that the real choice was between closure of the road and all other alternatives. Because this meta-consensus reduces the effective number of options to two, it would preclude manipulations such as introducing irrelevant alternatives, varying the order in which votes across multiple 
alternatives are taken, or proposing different voting systems. At any rate, and whatever form it takes, preference meta-consensus helps banish social choice theory's dire prognostications about both the arbitrariness and instability of democracy and its vulnerability to manipulation (Dryzek and List 2003). Mackie (2003) demonstrates at length that real political actors often find ways to locate dimensions with single-peaked preference orderings.

\section{The Limits of Meta-Consensus}

At this point we reach the tentative conclusion that ideals of consensus and pluralism in political interaction can be reconciled by the idea that consensus belongs at the metalevel while pluralism belongs at the simple level. Metaconsensus effectively reconciles theoretical arguments for pluralism on the one hand and consensus on the other. However, such a conclusion does not reach far enough. For meta-consensus might still be under the sway of ideological constriction. Elites can manipulate public opinion using arguments that invoke "symbolic" values and beliefs, as described by Edelman (1964). The idea here is to associate one's preferred outcomes with popular symbols (such as freedom) and undesired outcomes with unpopular symbols (for example, communism or terrorism). The effect is to privilege particular norms invoked by symbolic arguments over others, so that normative meta-consensus is manipulated.

For the individuals following appealing cues, symbolic politics provides a simple and cognitively cheap solution to the problem of constructing preferences in relation to complex problems. In a plural society, different sides may compete in symbolic manipulation. Instead of beginning with a settlement on premises (values, beliefs) to arrive at conclusions (policy preferences), premises or perspectives are invoked by elites to support particular conclusions. These premises will often involve relations of cause and effect and so influence the content of any epistemic meta-consensus. Particular factual claims can be deployed strategically in the interests of particular normative positions. So oil companies will finance studies that point to the absence of serious climate change resulting from increased carbon dioxide emissions, while environmentalists will make claims about imminent catastrophe unless greenhouse gas emissions are curbed. Almost all scientists recognize the reality of climate change caused by increasing carbon dioxide levels in the atmosphere resulting from fossil fuel use. Yet fossil fuel industry-financed scientists still try to extend the epistemic meta-consensus to cover thorough skepticism about anthropogenic climate change. Here, credibility judgments can be made based on the source of a claim. If a claim is backed only by science funded or undertaken by partisans, then it should not be accepted into an epistemic meta-consensus. On the climate change issue, this standard would rule out the consistently alarmist science of the Worldwatch Institute as well as the skepticism financed by the fossil fuel industry. To use Hume's terminology, reasons that are the slave of passions have no place in an epistemic meta-consensus.

A comparison of the localized hazardous pollution and global warming examples is instructive here. The local residents claiming health damage from hazardous pollution and fossil fuel corporations denying global warming are all acting to defend their own interests. However, there is a big difference between individuals expending time and energy to publicize perceived risks based on actual individual cases of death and disease on the one hand, and corporations financing studies designed to enhance their own profitability on the other. The former begin with evidence (however much it might be disputed by epidemiologists); the latter begin with an interest and seek evidence. The former can stimulate formation of a problem-solving public; the latter try to undermine the conditions for such joint problem solving.

By influencing meta-consensus at the level of values and beliefs, the kind of polarization that ensues under symbolic politics can, perhaps perversely, have the effect of increasing preference meta-consensus. In their study of preferences before and after a deliberative poll conducted on the issue of whether or not Australia should become a republic, McLean et al. (2000) show that the degree of preference meta-consensus (defined in List's terms as agreement on a single important dimension along which preferences are structured) was unchanged by deliberation. They attribute the prior preference meta-consensus to the high salience of the republic issue. However, an equally plausible explanation is that the prior metaconsensus was a function of manipulation by political leaders. A coalition of direct-election (for the presidency) republicans and monarchists successfully portrayed the indirect-election republic on offer as elitist, a "politician's republic." This coalition invoked a widely held belief that politicians cannot be trusted, which then became central in determining the content of epistemic meta-consensus. Consequently, the symbolically determined dimension along which preferences were structured was elitist to nonelitist. After deliberation, the dominant dimension changed to republican-monarchist.

Our discussion of the limits of meta-consensus suggests that meta-consensus can be the product of symbol manipulation as well as relatively uncoerced dialogue. 
What this might seem to suggest is that we need to introduce some procedural norms for the evaluation of particular instances of meta-consensus. One candidate would be Habermasian standards of communicative rationality.

Now, invoking Habermas might produce a negative response on the part of pluralists who associate him with consensus. But many of their objections to Habermasian procedural conditions of consensus at the simple level are attenuated (if not actually eliminated) by a move to the meta level. Meta-consensus by definition allows for diversity in values, beliefs, and preferences. We have shown that all pluralists, be they liberal or critical, must in the end appeal to some kind of meta-consensus to regulate pluralism. If so, pluralists cannot avoid contemplation of the conditions under which meta-consensus gets produced or discovered. Pluralists do not have to endorse Habermasian procedural standards at the meta level, but it should not be hard for them to accept that any metaconsensus reached under these conditions is preferable to one reached through symbolic manipulation as captured by Edelman. Agonists might still insist that any such metaconsensus remain provisional and contestable, and that is fair enough-especially when it comes to issues involving fundamental conflict of identity.

\section{Conclusion}

It makes little sense to be for pluralism, against pluralism, for consensus, or against consensus. We have argued that competing ideals of pluralism and consensus can be reconciled by pluralism at the simple level combined with meta-consensus on values, beliefs, and preferences. However, close attention must be paid to the content of meta-consensus, as well as its conditions of production.

When it comes to content, we should avoid both overspecification and underspecification. Overspecification of normative meta-consensus can be found, for example, in the lessons Gutmann and Thompson draw for the substance of moral principles and content of public policy from their principle of reciprocity. Other examples of overspecification might refer to the content of an issue dimension along which preferences should be arrayed, if it is specified by an observer rather than discovered by participants, or allowing competing scientific viewpoints into epistemic meta-consensus while scorning lay knowledge. Underspecification characterizes agonism in its keenness to make normative meta-consensus itself contestable. However defensible this might be for the kind of identity conflicts that preoccupy agonists, it is a poor general principle. Underspecification of epistemic metaconsensus could approach "anything goes" in knowledge claims. When it comes to the conditions of its production, meta-consensus produced by symbolic politics in the service of partisans or (worse) hegemonic actors is much less defensible than meta-consensus produced by relatively uncoerced dialogue.

Our emphasis on meta-consensus might seem to leave open the question of how collective decisions get made. But whatever the mechanism used (short of dictatorship), be it majority rule, approval voting, unanimity, bargained resolution, or agreements that majorities support and $\mathrm{mi}-$ norities can live with, meta-consensus makes collective choice more tractable. Sometimes tractability will enable agreement on what is to be done, but other kinds of outcome are possible: for example, different rules for different parts of the community (as in the HIV-AIDS example), or a decision supported by majority vote. Enhanced tractability can occur in different ways, depending on the kind of meta-consensus secured. Normative metaconsensus involves recognition across difference, and as such facilitates cooperative search for mutually acceptable solutions to joint problems while respecting value differences that can remain deep and irreconcilable, as the case of dialogue on HIV-AIDS policy illustrates. Aside from facilitating normative and preference meta-consensus, epistemic meta-consensus for its part can enable creation of a problem-solving public, as the example of epidemiological and local experiences of risks from hazardous pollution illustrates. Preference meta-consensus renders collective choice less vulnerable to strategizing and manipulation, by either producing agreement on the dimension along which choice can be structured, or reducing the effective number of options, as our Bloomfield Track example illustrates. The benefits of preference metaconsensus can be demonstrated most straightforwardly in situations where some kind of voting determines social choices-but these kinds of effects are generalizable to any mechanism for making collective choices, whether or not formal votes are taken.

In terms of the practical implications of this analysis for deliberators and facilitators (in any institutional setting), we suggest the following:

- Normative meta-consensus is especially urgent in situations featuring deep difference in identities and value commitments.

- Attention to the bounds of epistemic meta-consensus is especially important in settings where powerful actors invoke questionable empirical claims in support of their material interests. 
- Preference meta-consensus matters most in situations where one or more actors is in a position to manipulate decision processes (through, for example, the range of options on the agenda or the order in which votes are taken).

To recognize these benefits is not to imply that any meta-consensus should be applauded, and we have pointed to the possibility of symbolic distortion in its production. But to recognize this limit means only that we need to be on guard-not that the pursuit of metaconsensus should be shunned. Recall that for Cohen, "Outcomes are democratically legitimate if and only if they could be the object of free and reasoned agreement among individuals." We conclude instead: "Outcomes are democratically legitimate to the degree they are structured by free and reasoned meta-consensus among individuals subject to them."

\section{References}

Berlin, Isaiah. 1969. Four Essays on Liberty. Oxford: Oxford University Press.

Black, Duncan. 1948. "On the Rationale of Group DecisionMaking." Journal of Political Economy 56(1):23-34.

Bohman, James. 1998. "The Coming of Age of Deliberative Democracy." Journal of Political Philosophy 6(4):400-425.

Cohen, Joshua. 1989. "Deliberation and Democratic Legitimacy." In The Good Polity, ed. Alan Hamlin and Philip Pettit. Oxford: Basil Blackwell, pp. 17-34.

Connolly, William. 1991. Identity/Difference: Democratic Negotiations of Political Paradox. Ithaca: Cornell University Press.

Dewey, John. 1927. The Public and Its Problems. New York: Henry Holt and Co.

Dryzek, John S. 1990. Discursive Democracy: Politics, Policy and Political Science. Cambridge: Cambridge University Press.

Dryzek, John S., and Christian List. 2003. "Social Choice Theory and Deliberative Democracy: A Reconciliation." British Journal of Political Science 33(1):1-28.

Dworkin, Ronald. 1977. Taking Rights Seriously. Cambridge: Harvard University Press.

Edelman, Murray J. 1964. The Symbolic Uses of Politics. Urbana: University of Illinois Press.

Elster, Jon. 1986a. “The Market and the Forum.” In Foundations of Social Choice Theory, ed. Jon Elster and Aanund Hylland. Cambridge: Cambridge University Press, pp. 103-32.

Elster, Jon, ed. 1986b. The Multiple Self. Cambridge: Cambridge University Press.

Elster, Jon. 1998. "Deliberation and Constitution Making." In Deliberative Democracy, ed. Jon Elster. New York: Cambridge University Press, pp. 97-122.

Femia, Joseph. 1996. "Complexity and Deliberative Democracy.” Inquiry 39(3-4):359-97.

Forester, John. 1999. “Dealing with Deep Value Difference.” In The Consensus-Building Handbook, ed. Lawrence Susskind,
Sarah McKearnan, and Jennifer Thomas-Larmer. Thousand Oaks, CA: Sage, pp. 463-94.

Galston, William A. 2002. Liberal Pluralism: The Implications of Value Pluralism for Political Theory and Practice. Cambridge: Cambridge University Press.

Goodin, Robert E. 1986. "Laundering Preferences.” In Foundations of Social Choice Theory, ed. Jon Elster and Aanund Hylland. Cambridge: Cambridge University Press, pp. 75102.

Gray, John. 1996. Isaiah Berlin. Princeton: Princeton University Press.

Gutmann, Amy, and Dennis Thompson. 1996. Democracy and Disagreement. Cambridge: The Belknap Press.

Habermas, Jürgen. 1996. Between Facts and Norms: Contributions to a Discourse Theory of Law and Democracy. Cambridge: MIT Press.

Honig, Bonnie. 1993. Political Theory and the Displacement of Politics. Ithaca: Cornell University Press.

Honig, Bonnie. 1996. "Difference, Dilemmas, and the Politics of Home." In Democracy and Difference: Contesting the Boundaries of the Political, ed. Seyla Benhabib. Princeton: Princeton University Press, pp. 25777.

Hughes, Michael A., with John Forester and Irene Weiser. 1999. "Facilitating Statewide HIV/AIDS Policies and Priorities in Colorado." In The Consensus-Building Handbook, ed. Lawrence Susskind, Sara McKearnan, and Jennifer Thomas-Larmer. Thousand Oaks, CA: Sage, pp. 101129.

Knight, Jack, and James Johnson. 1994. "Aggregation and Deliberation: On the Possibility of Democratic Legitimacy.” Political Theory 22(2):277-96.

Kuhn, Thomas. 1970. The Structure of Scientific Revolutions. Chicago: Chicago University Press.

Kuran, Timur. 1998. "Insincere Deliberation and Democratic Failure." Critical Review 12(4):529-44.

Lijphart, Arend. 1977. Democracy in Plural Societies: A Comparative Exploration. New Haven: Yale University Press.

List, Christian. 2002. "Two Conceptions of Agreement." The Good Society 11(1):72-79.

MacIntyre, Alastair. 1984. "Does Applied Ethics Rest on a Mistake?” The Monist 67(4):498-513.

MacIntyre, Alastair. 1988. Whose Justice? Which Rationality? Notre Dame: University of Notre Dame Press.

Mackie, Gerry. 2003. Democracy Defended. Cambridge: Cambridge University Press.

Manin, Bernard. 1987. "On Legitimacy and Political Deliberation." Political Theory 15(3):338-68.

McLean, Iain, Christian List, James Fishkin, and Robert Luskin. 2000. "Can Deliberation Induce Greater Preference Structuration? Evidence from Deliberative Opinion Polls.” Presented at the Annual Meeting of the American Political Science Association, Washington.

Mouffe, Chantal. 1996. "Democracy, Power and 'The Political."” In Democracy and Difference: Contesting the Boundaries of the Political, ed. Seyla Benhabib. Princeton: Princeton University Press, pp. 245-56.

Mouffe, Chantal. 1999. "Deliberative Democracy or Agonistic Pluralism?” Social Research 66(3):745-58. 
Mouffe, Chantal. 2000. The Democratic Paradox. London: Verso.

Niemeyer, Simon J. 2002. Deliberation in the Wilderness: Transforming Policy Preferences Through Discourse. Ph.D. thesis. The Australian National University.

Niemeyer, Simon J. 2004. "Deliberation in the Wilderness: Displacing Symbolic Politics.” Environmental Politics 13(2):34772.

Popper, Karl R. 1966. The Open Society and Its Enemies. London: Routledge and Kegan Paul.

Rawls, John. 1993. Political Liberalism. New York: Columbia University Press.

Rescher, Nicholas. 1993. Pluralism: Against the Demand for Consensus. Oxford: Clarendon Press.

Riker, William H. 1982. Liberalism Against Populism: A Confrontation Between the Theory of Democracy and the Theory of Social Choice. San Francisco: Freeman.

Rokeach, Milton. 1979. Understanding Human Values: Individual and Societal. New York: Free Press.

Schlosberg, David. 1999. Environmental Justice and the New Pluralism: The Challenge of Difference for Environmentalism. Oxford: Oxford University Press.
Sunstein, Cass R. 1995. "Incompletely Theorized Agreements." Harvard Law Review 108:1733-72.

Susskind, Lawrence, Sara McKearnan, and Jennifer ThomasLarmer ed. 1999. The Consensus-Building Handbook. Thousand Oaks, CA: Sage.

Tesh, Sylvia Noble. 2000. Uncertain Hazards: Environmental Activists and Scientific Proof. Ithaca: Cornell University Press.

Waldron, Jeremy. 2004. "Liberalism, Political and Comprehensive." In The Handbook of Political Theory, ed. Gerald Gaus and Chandran Kukathas. London: Sage, pp. 8999.

Young, Iris Marion. 1996. "Communication and the Other: Beyond Deliberative Democracy." In Democracy and Difference: Contesting the Boundaries of the Political, ed. Seyla Benhabib. Princeton: Princeton University Press, pp. 12035.

Young, Iris Marion. 2000. Inclusion and Democracy. Oxford: Oxford University Press.

Zablocki, Benjamin. 1980. Alienation and Charisma: A Study of Contemporary American Communes. New York: Free Press. 